\title{
Gonadotrophin levels in male voles (Microtus agrestis) reared in long and short photoperiods
}

\author{
R. P. Craven and J. R. Clarke* \\ Department of Biology, Oxford Polytechnic, Headington, Oxford OX3 OBP, and * Department of \\ Agricultural and Forest Sciences, University of Oxford, Agricultural Science Building, Parks Road, \\ Oxford $O X I 3 P F, U . K$.
}

\begin{abstract}
Summary. Male voles were reared from birth to the age of 56 days in photoperiods of $16 \mathrm{~L}: 8 \mathrm{D}$ or $6 \mathrm{~L}: 18 \mathrm{D}$. In $16 \mathrm{~L}: 8 \mathrm{D}$ testes increased 10 -fold in size between the age of 14 and 56 days, and there were concomitant increases in diameter of seminiferous tubules and seminal vesicle weight. Spermatozoa were present in tubules by 35 days. In $6 \mathrm{~L}: 18 \mathrm{D}$ no significant changes with age occurred in testis size, diameter of seminiferous tubules or seminal vesicle weight. LH secretion increased with age in $16 \mathrm{~L}: 8 \mathrm{D}$, but not in $6 \mathrm{~L}: 18 \mathrm{D}$, and pituitary and plasma levels were higher in the former than in the latter by 35 days. Pituitary levels of FSH were high up to 21 days in $16 \mathrm{~L}: 8 \mathrm{D}$, and up to 35 days in $6 \mathrm{~L}: 18 \mathrm{D}$. At 35 days the mean pituitary level was significantly higher in the $6 \mathrm{~L}: 18 \mathrm{D}$ than in $16 \mathrm{~L}: 8 \mathrm{D}$. Plasma levels of FSH were significantly higher in $16 \mathrm{~L}: 8 \mathrm{D}$ at 14 and 21 days, and then gradually declined. In $6 \mathrm{~L}: 18 \mathrm{D}$ plasma FSH rose to a maximum at 35 days, but did not reach the levels occurring at an earlier age in voles in 16L :8D. The relationship between pituitary and plasma levels of FSH in the two photoperiods is compatible with the idea of a storage and a readily releasable pool of the hormone within the pituitary gland. In $16 \mathrm{~L}: 8 \mathrm{D}$ changing levels of LH and FSH seem to be due to the onset of testicular activity with consequent feedback effects of testicular hormones upon the anterior pituitary gland.
\end{abstract}

\section{Introduction}

Long days or long artificial photoperiods allow more rapid testicular growth and development in the vole (Microtus agrestis) than short ones (Baker \& Ranson, 1932, 1933; Clarke \& Kennedy, 1967; Grocock \& Clarke, 1974; Grocock, 1979). The amounts of 'total gonadotrophin' and of LH in the anterior pituitary are higher in sexually mature males trapped during the breeding season than in sexually inactive animals from the field in winter (Clarke \& Forsyth, 1964a; Worth, Charlton \& MacKinnon, 1973). As part of a study of the causes of seasonal breeding in the vole we have measured pituitary and plasma levels of LH and FSH in voles reared from birth in long or short photoperiods.

\section{Materials and Methods}

All animals were from the closed colony maintained in the Department of Agricultural and Forest Sciences, Oxford. They were housed and fed as described by Grocock \& Clarke (1974). Pregnant females were transferred from the Animal House, where the photoperiod is $16 \mathrm{~h}$ light: $8 \mathrm{~h}$ dark 
(16L:8D), to light-proof cabinets in which the lighting regimen was $16 \mathrm{~L}: 8 \mathrm{D}$ or $6 \mathrm{~L}: 18 \mathrm{D}$. The subsequent litters were reared in the photoperiod prevailing at their birth. Young were weaned at the age of 16 days, and males were kept 4-6 to a cage in the lighting conditions in which they were born. Between 10:00 and 12:00 h at the age of 14,21,28,36,42 and 56 days animals were anaesthetized with ether and terminal blood samples taken into heparinized syringes. The blood was centrifuged and the plasma stored at $-20^{\circ} \mathrm{C}$ until assayed. Pituitary glands (including the posterior lobe) were removed immediately after death, weighed and also stored at $-20^{\circ} \mathrm{C}$ until assayed. Carcases were fixed in $10 \%$ formalin, and paired testes and seminal vesicles later weighed. Paraffin-wax sections of testes $(8 \mu \mathrm{m})$ were prepared by standard methods and stained with Ehrlich's haematoxylin and eosin. The widths of 10 seminiferous tubules in each of 10 widely separated testicular sections from each animal were measured. From these values a single best estimate of width for each animal was obtained.

Pituitaries were homogenized in phosphate-buffered saline, $\mathrm{pH}$ 7. In agreement with the findings of Worth (1973) dilutions of plasma from castrated voles and of vole pituitary homogenates reacted with anti-ovine LH and anti-rat FSH to produce dilution curves parallel to those for ovine and rat standards (Text-fig. 1). LH and FSH were therefore measured by a heterologous double-antibody radioimmunoassay, using the ultra-microassay described by Naftolin \& Corker (1971) and Worth (1973). Antiserum to ovine LH and ovine LH for iodination were kindly provided by Professor G. D. Niswender and Professor L. E. Reichert, respectively. Antiserum to rat FSH, rat FSH for iodination, and the reference preparations (ovine LH, S19; rat FSH, RP-1) were generously given by the NIAMDD, NIH, Bethesda, U.S.A. All standards and most of the unknowns were measured in triplicate. Some samples of plasma were only sufficient to allow duplicate measurements. The lowest detectable levels were $0.15 \mathrm{ngLH} / \mathrm{ml}$ and $21 \mathrm{ng} \mathrm{FSH} / \mathrm{ml}$. Inter- and intra-assay coefficients of variation were, respectively, 8.6 and $5.4 \%$ for $\mathrm{LH}$ and 7.5 and $7.8 \%$ for FSH. Data were analysed by analysis of variance and the $t$ test for the significance of differences between means. Values of $P<0.05$ have been regarded as indicating statistical significance.
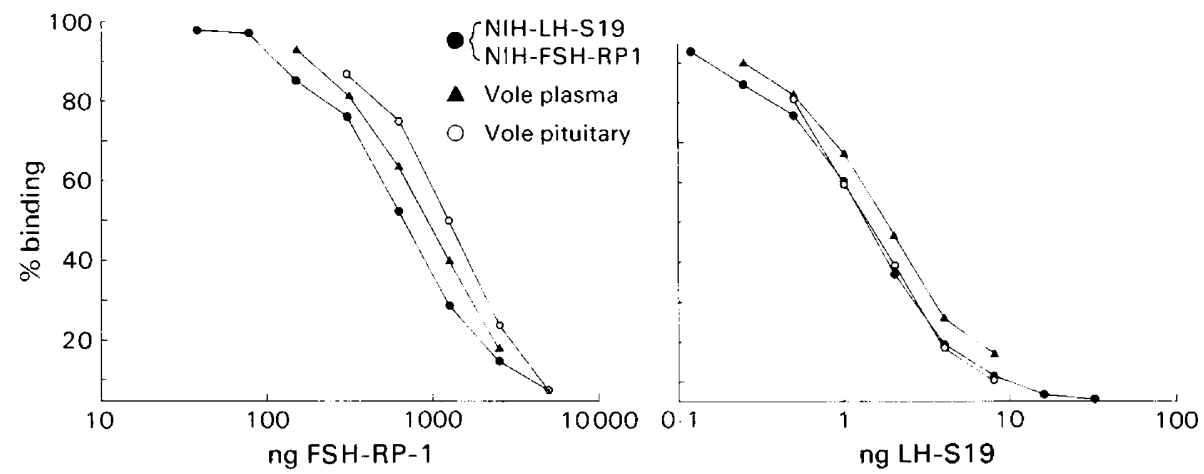

Text-fig. 1. Dilution curves of vole pituitary homogenates, vole plasma, NIH-LH-S19 and NIH-FSHRP-1 incubated with anti-ovine LH and anti-rat FSH.

\section{Results}

\section{Changes in testes and seminal vesicles}

There were significant changes with age in the weights of testes and seminal vesicles of voles living in $16 \mathrm{~L}: 8 \mathrm{D}$ but not in those of animals from $6 \mathrm{~L}: 18 \mathrm{D}$ (Text-fig. 2). The greatest relative change in weight occurred between 14 and 21 days. Testes and seminal vesicles were significantly 


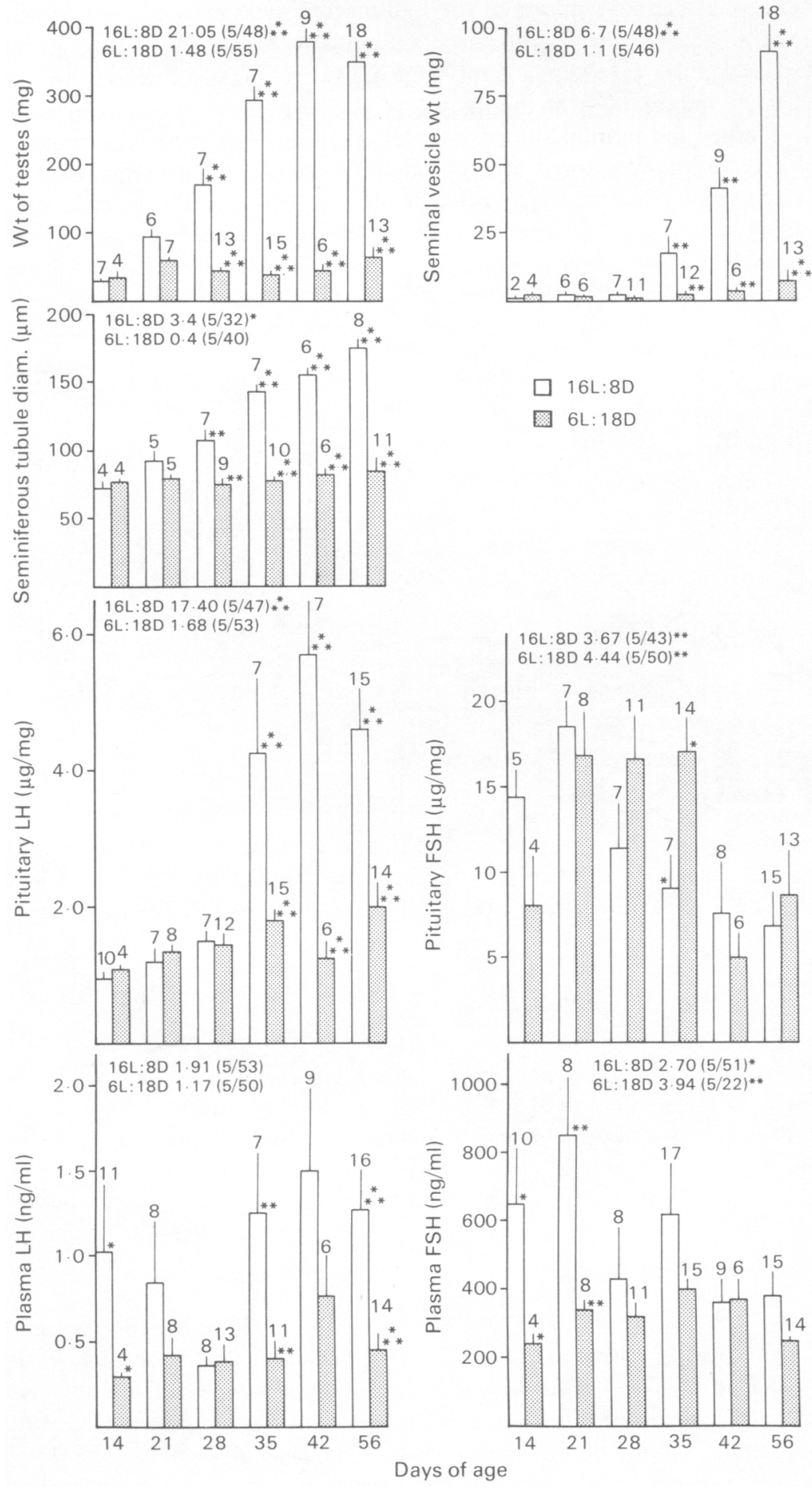

Text-fig. 2. Weights of testis and seminal vesicles, seminiferous tubule diameters, and plasma and pituitary concentrations of LH and FSH in voles exposed from birth to long or short photoperiods. Values are mean \pm s.e.m. for the sample sizes indicated. F ratios from analysis of variance, and degrees of freedom are also given. ${ }^{*} P<0.05,{ }^{* *} P<0.01,{ }^{* * *} P<0.001$. 
heavier in animals from $16 \mathrm{~L}: 8 \mathrm{D}$ than in those from $6 \mathrm{~L}: 18 \mathrm{D}$, at and after the ages of 21 and 35 days respectively. The diameter of seminiferous tubules increased significantly in the $16 \mathrm{~L}: 8 \mathrm{D}$ voles from 14 to 56 days, the relative change in diameter being greater from 14 to 21 and 28 to 35 days than at other intervals. No statistically significant change in tubule diameter occurred in voles from $6 \mathrm{~L}: 18 \mathrm{D}$. Tubules from animals living in $16 \mathrm{~L}: 8 \mathrm{D}$ were significantly wider than those of animals in $6 \mathrm{~L}: 18 \mathrm{D}$ at and after the age of 28 days. Spermatozoa were present from 35 days in testes of animals kept in $16 \mathrm{~L}: 8 \mathrm{D}$, but none were seen in testes of the $6 \mathrm{~L}: 18 \mathrm{D}$ animals.

\section{Pituitary and plasma levels of gonadotrophins}

Pituitary weights increased significantly with age from $0.5-0.6 \mathrm{mg}$ at 14 days to $0.8-0.9 \mathrm{mg}$ at 56 days in each photoperiod. There were no significant differences in pituitary weight between the two photoperiod treatments. Analysis of variance showed that LH levels in the pituitary changed significantly with age in $16 \mathrm{~L}: 8 \mathrm{D}$ but not in $6 \mathrm{~L}: 18 \mathrm{D}$ (Text-fig. 2 ). In $16 \mathrm{~L}: 8 \mathrm{D}$ mean values were significantly higher at 35,42 and 56 days than at 14,21 and 28 days, or than any age in the short photoperiod. There was no overall change with age in plasma levels of LH in either photoperiod, although in 16L : 8D mean values at 42 and 56 days were significantly higher than at 28 days. Plasma levels in $16 \mathrm{~L}: 8 \mathrm{D}$ were significantly higher than in $6 \mathrm{~L}: 18 \mathrm{D}$ at 35 and 56 days. In both photoperiods there was a significant overall change with age in pituitary and plasma levels of FSH. In $16 \mathrm{~L}: 8 \mathrm{D}$ the mean pituitary level at 21 days was significantly higher than at later ages. Likewise, the plasma level of FSH in $16 \mathrm{~L}: 8 \mathrm{D}$ was highest at 21 days, differing significantly from values at 28 , 42 and 56 days. In $6 \mathrm{~L}: 18 \mathrm{D}$ the mean pituitary level of FSH was significantly higher at 21 than at 14 days. Levels were sustained until 35 days, and then there was a significant decline. The mean value for plasma FSH in $6 \mathrm{~L}: 18 \mathrm{D}$ was significantly higher at 35 than at 14 or 56 days. Pituitary FSH values at 14 days appeared to be higher in $16 \mathrm{~L}: 8 \mathrm{D}$ than in $6 \mathrm{~L}: 18 \mathrm{D}$, but the difference was not statistically significant $(P=0 \cdot 06)$. However, at 21 days pituitary levels were the same in the two treatments and by 35 days the mean value in $6 \mathrm{~L}: 18 \mathrm{D}$ was significantly higher than that in $16 \mathrm{~L}: 6 \mathrm{D}$. At 42 and 56 days means for the two photoperiods were not different. Plasma levels were significantly higher in $16 \mathrm{~L}: 8 \mathrm{D}$ than in $6 \mathrm{~L}: 18 \mathrm{D}$ at 14 and 21 days, but not thereafter.

\section{Discussion}

Two different aspects of these results deserve comment: (1) the change with age in various measures of sexual development, and (2) the effect of long or short photoperiods upon sexual development. The effect of age and photoperiod on testicular development is quite straightforward and in agreement with the results of Grocock (1979). Testes from voles living in the long photoperiod become progressively larger, and, judged by the size and state of seminiferous tubules and by seminal vesicle weight, more active than those from the short photoperiod, which do not change over the age range studied.

Age and photoperiod effects have also been demonstrated on the synthesis and release of gonadotrophins from the pituitary gland. The changes with age in the $16 \mathrm{~L}: 8 \mathrm{D}$ treatment in plasma levels of LH and FSH resemble those reported for the developing rat (Swerdlof, Walsh, Jacobs \& Odell, 1971; Döhler \& Wuttke, 1975; Lee, de Kretser, Hudson \& Wang, 1975; Piacsek \& Goodspeed, 1978). The two effects are shown most clearly for pituitary levels of LH, which increased with age in $16 \mathrm{~L}: 8 \mathrm{D}$ to become significantly higher than those of voles in $6 \mathrm{~L}: 18 \mathrm{D}$ after 28 days. Although there was no overall age effect in either photoperiod upon plasma LH values, the mean level was significantly higher in the long than short photoperiod at 35 and 56 days. It is apparent that in 16L: $8 \mathrm{D}$ between the ages of 28 and 35 days synthesis and release of LH are appreciably increased. In the same interval there is a considerable relative enlargement of the seminal vesicles 
in voles from $16 \mathrm{~L}: 8 \mathrm{D}$. These facts presumably represent a causal sequence, the increased synthesis and release of $\mathrm{LH}$ causing a rise in androgen levels, which provokes seminal vesicle growth. The short photoperiod prevents this from happening. The occurrence in $16 \mathrm{~L}: 8 \mathrm{D}$ of high levels of pituitary and plasma LH while the release of androgen appears to be increasing may be caused by alteration in the sensitivity of the hypothalamo-hypophysial system to negative feedback effects of androgen, and of the pituitary to stimulation by GnRH (Davies \& Bicknell, 1976; Davies, Goulden, Follett \& Brown, 1976; Lincoln, 1976, 1977). The pituitary and plasma levels of LH found in this study are similar to those reported by Worth et al. (1973) who studied male voles from the field and the laboratory: Values changed with season or with conditions of lighting in a fashion consistent with the differences we have found between voles living in long and short photoperiods.

Age and photoperiod had an influence upon pituitary and plasma levels of FSH in 16L:8D and $6 \mathrm{~L}: 18 \mathrm{D}$. By the age of 21 days the pituitary seems able to synthesize FSH equally well in long and short photoperiods. However, its capacity to release FSH is, at early ages, appreciably greater in $16 \mathrm{~L}: 8 \mathrm{D}$ than in $6 \mathrm{~L}: 18 \mathrm{D}$. After the age of 21 days synthesis and release decline in voles from the long photoperiod, while synthesis is sustained in the short photoperiod so that by the age of 35 days pituitary levels of FSH are higher in $6 \mathrm{~L}: 18 \mathrm{D}$ than in $16 \mathrm{~L}: 8 \mathrm{D}$. Plasma FSH values in $6 \mathrm{~L}: 18 \mathrm{D}$ are greater at 35 days than at other ages, but do not reach the level found at 21 days in $16 \mathrm{~L}: 8 \mathrm{D}$. In the long photoperiod testes and seminiferous tubules undergo considerable relative change in size between 14 and 21 days. These testicular changes may be caused by the higher release of FSH, which initiates seminiferous tubule growth and promotes spermatogenesis (Raj \& Dym, 1976; Courot et al., 1979). Negative feedback of a substance (inhibin?) arising from seminiferous tubules may then cause the reduction in FSH secretion and release observed in 16L:8D after the age of 21 days (Cahoreau, Blanc, Dacheux, Pisselet \& Courot, 1979; Davies, Main, Laurie \& Setchell, 1979; Sheth, Joshi, Moodbidri \& Rao, 1979). Androgen from the interstitial tissue may be sufficient to maintain spermatogenesis once it has been established (Dym et al., 1979).

The contrast between the long and short photoperiods in the relationship between pituitary synthesis and release of FSH suggests the occurrence within the pituitary of a storage and a readily releasable pool of FSH, as has been suggested for LH (Lincoln, 1976, 1977; Pickering \& Fink, 1979). This is inferred from the observation that in $16 \mathrm{~L}: 8 \mathrm{D}$ at 21 days synthesis and release of FSH are high, but in $6 \mathrm{~L}: 18 \mathrm{D}$ synthesis at 21,28 and 35 days is essentially the same as at 21 days in $16 \mathrm{~L}: 8 \mathrm{D}$, but release is very much lower. The size of each pool, and the transfer of hormone from one to the other, could be regarded as being influenced by photoperiod and also by feedback from the testes. Long photoperiods allow both pools to be large at an early age before the testes develop; short photoperiods can sustain a storage pool for a while. The slight, though statistically significant, rise and fall in plasma FSH in 6L:18D suggests some limited capacity to release FSH, which may be reduced by negative feedback from the testes. The hypothalamo-hypophysial system is thought to be very much more sensitive to negative feedback effects of gonadal hormones in non-stimulatory than in stimulatory photoperiods (for review, see Clarke, 1981). Methods other than those used here for the assessment of testicular activity would be necessary to disclose the existence and source of such a feedback from the testes of voles in $6 \mathrm{~L}: 18 \mathrm{D}$.

The present results for the first 56 days of life afford some insight into changing gonadotrophin output in males during the transition under a long photoperiod from the pre- to post-pubertal state, as occurs under field conditions each spring for young of that year. Voles exposed from birth to short photoperiods have a low output of gonadotrophins and remain in a prepubertal state; they may be representative of wild voles that are born late in the breeding season and in which sexual development is inhibited by the onset of unfavourable autumn conditions (Clarke \& Forsyth, 1964b; Clarke \& Kennedy, 1967). In a number of mammals mean pituitary and plasma levels of FSH and LH are higher in the breeding than the non-breeding season (see Clarke, 1981). Changes in the frequency of plasma pulses of LH occur in sheep as they pass from a non-stimulatory to a stimulatory photoperiod (Lincoln \& Short, 1980), but the sampling techniques used for sheep may be very difficult to apply to small mammals such as the vole. 
We are indebted to Dr G. Fink, Miss Vivienne Langford, Mr R. Laynes, Dr P. C. B. MacKinnon, Mrs Susan Wong and Miss Janet Stewart for help with this investigation; Professor G. D. Niswender, Professor L. E. Reichert, and the N.I.A.M.D., for the supply of hormones and antibodies; and to the Smith Kline \& French Foundation and the Royal Society for grants covering part of the cost of materials and equipment. The investigation was carried out under a grant to J.R.C. from the Medical Research Council (MRC G.974/297/B).

\section{References}

Baker, J.R. \& Ranson, R.M. (1932) Factors affecting the breeding of the field mouse (Microtus agrestis). Part I. Light. Proc. R. Soc. B 110, 313-322.

Baker, J.R. \& Ranson, R.M. (1933) Factors affecting the breeding of the field mouse (Microtus agrestis). Part III. Locality. Proc. $R$. Soc. B 113, 486-495.

Cahoreau, C., Blanc, M.R., Dacheux, J.L., Pisselet, C. \& Courot, M. (1979) Inhibin activity in ram testis fluid: depression of plasma FSH and LH in the castrated and cryptorchid ram. J. Reprod. Fert., Suppl. 26, 97116.

Clarke, J.R. (1981) Physiological problems of seasonal breeding in eutherian mammals. In Oxford Reviews of Reproductive Biology, Vol. 3, pp. 244-312. Ed. C. A. Finn. Clarendon Press, Oxford.

Clarke, J.R. \& Forsyth, I.A. (1964a) Seasonal changes in the adenohypophysis of the vole (Microtus agrestis). Gen. comp. Endocr. 4, 243-252.

Clarke, J.R. \& Forsyth, I.A. (1964b) Seasonal changes in the gonads and accessary reproductive organs of the vole (Microtus agrestis). Gen. comp. Endocr. 4, 233242.

Clarke, J.R. \& Kennedy, J.P. (1967) Effect of light and temperature upon gonadal activity in the vole (Microtus agrestis). Gen comp. Endocr. 8, 474-488.

Courot, M., Hochereau-de-Reviers, M.-T., Monet-Kuntz, C., Locatelli, A., Pisselet, C., Blanc, M.R. \& Dacheux, J.L. (1979) Endocrinology of spermatogenesis in the hypophysectomized ram. J. Reprod. Fert., Suppl. 26, 165-173.

Davies, D.T. \& Bicknell, R.J. (1976) The effect of testosterone on the responsiveness of the quail's pituitary to luteinizing hormone-releasing hormone (LH-RH) during photoperiodically induced testicular growth. Gen. comp. Endocr. 30, 487-499.

Davies, D.T., Goulden, L.P., Follett, B.K. \& Brown, N.L. (1976) Testosterone feedback on luteinizing hormone (LH) secretion during a photoperiodically induced breeding cycle in Japanese quail. Gen. comp. Endocr. 30, $477-486$.

Davies, R.V., Main, S.J., Laurie, M.S. \& Setchell, B.P. (1979) The effects of long-term administration of either a crude inhibin preparation or an antiserum to FSH on serum hormone levels, testicular function and fertility of adult male rats. J. Reprod. Fert., Suppl. 26, 183-191.

Döhler, K.D. \& Wuttke, W. (1975) Changes with age in levels of serum gonadotropin, prolactin and gonadal steroids in prepubertal male and female rats. Endocrinology 97, 898-907.

Dym, M., Raj, H.G.M., Lin, Y.C., Chemes, H.E., Kotite, N.J., Nayfeh, S.N. \& French, F.S. (1979) Is FSH required for maintenance of spermatogenesis in adult rats? J. Reprod. Fert., Suppl. 26, 175-181.
Grocock, C.A. (1979) Testis development in the vole $M i$ crotus agrestis, subjected to long or short photoperiods from birth. J. Reprod. Fert. 55, 423-427.

Grocock, C.A. \& Clarke, J.R. (1974) Photoperiodic control of testis activity in the vole, Microtus agrestis. $J$. Reprod. Fert. 39, 337-347.

Lee, V.W.K., de Kretser, D.M., Hudson, B. \& Wang, C. (1975) Variations in serum FSH, LH and testosterone levels in male rats from birth to sexual maturity. $J$. Reprod. Fert. 42, 121-126.

Lincoln, G.A. (1976) Seasonal variation in the episodic secretion of luteinizing hormone and testosterone in the ram. J. Endocr. 69, 213-226.

Lincoln, G.A. (1977) Changes in pituitary responsiveness to luteinizing hormone releasing hormone in rams exposed to artificial photoperiods. J. Endocr. 73, 519527.

Lincoln, G.A. \& Short, R.V. (1980) Seasonal breeding: nature's contraceptive. Recent Prog. Horm. Res. 36, $1-52$.

Naftolin, F. \& Corker, C.S. (1971) An ultramicro method for the measurement of luteinising hormone by radioimmunoassay. In Radioimmunoassay Methods, p. 641. Eds K. E. Kirkham \& W. H. Hunter. Churchill, London.

Piacsek, B.E. \& Goodspeed, M.P. (1978) Maturation of the pituitary-gonadal system in the male rat. $J$. Reprod. Fert. 52, 29-35.

Pickering, A. J-M.C. \& Fink, G. (1979) Variation in size of the 'readily releasable pool' of luteinizing hormone during the oestrous cycle of the rat. $J$. Endocr. 83, 5359.

Raj, H.G.M. \& Dym, M. (1976) The effects of selective withdrawal of FSH and LH on spermatogenesis in the immature rat. Biol. Reprod. 14, 489-494.

Sheth, A.R., Joshi, L.R., Moodbidri, S.B. \& Rao, S.S. (1979) Characterization of a gonadal factor involved in the control of FSH secretion. J. Reprod. Fert., Suppl. 26, 71-85.

Swerdlof, R.S., Walsh, P.C., Jacobs, H.S. \& Odell, W.D. (1971) Serum LH and FSH during sexual maturation in the male rat: effect of castration and cryptorchidism. Endocrinology 88, 120-128.

Worth, R.W. (1973) Some aspects of the structure and function of the pituitary gland of the common shorttailed field vole (Microtus agrestis). D.Phil. thesis, University of Oxford.

Worth, R.W., Chariton, H.M. \& MacKinnon, P.C.B. (1973) Field and laboratory studies on the control of luteinizing hormone secretion and gonadal activity in the vole, Microtus agrestis. J. Reprod. Fert., Suppl. 19, 89-99. 